\title{
Editorial
}

\section{Health care economics in neurosurgery: there is no turning back}

\author{
Nancy McLaughlin, M.D., Ph.D., F.R.C.S.C., ${ }^{1}$ \\ AleXander A. Khalessi, M.D., M.S., \\ and Neil A. Martin, M.D. ${ }^{1}$
}

\begin{abstract}
${ }^{1}$ Department of Neurosurgery, David Geffen School of Medicine, University of California, Los Angeles; and ${ }^{2}$ Department of Neurosurgery, University of California, San Diego, California
\end{abstract}

Although we as physicians have developed knowledge and expertise in reporting and analyzing clinical outcome, costs remain for most neurosurgeons a no-man's-land, or perhaps a lonely-man's-land, with very few engaged in health economics. This will need to change as health care delivery and financing in the US undergoes a period of seismic transformation. These changes carry dramatic implications for referral patterns, hospital-physician partnerships, configuration of health care networks, patient access to the full range of procedures and technologies, and the training environment of future neurosurgeons. ${ }^{?}$

Although growth in US health care spending remained stable in 2013 (approximately 4\%), health care continues to command a greater annual share of gross domestic product. Given that 11 million Americans are projected to gain health insurance coverage in 2014, expected growth in spending is $6.1 \%$ (http://www.cms.gov/ research-statistics-data-and-systems/statistics-trendsand-reports/nationalhealthexpenddata/downloads/ proj2012.pdf). These massive structural pressures will force a stronger accounting of health care costs and demand more efficient neurosurgical practice in a resourceconstrained environment.

In 2013, the Centers for Medicare \& Medicaid Services fundamentally changed physician and hospital reimbursement. ${ }^{2,11}$ Under the Hospital Value-Based Purchasing program, Medicare spending per beneficiary is tracked from 7 days before hospitalization until 30 days afterwards. As a harbinger of diminishing resources, more hospitals received penalties than bonuses in 2013.

Moreover, the efficiency measure will represent a $20 \%$ share of global value assessment (Medicare payment) in 2015. Physician reimbursement will be determined by similar clinical process, patient experience, outcomes, and efficiency components. Given the complexity of neurosurgical patients, direct physician en- gagement in risk adjustment will be essential to prevent disproportionate cuts in funding for centers managing the sickest patients.

"Understanding costs could be the single most powerful lever to transform the value of health care." 5 This edition of Neurosurgical Focus aims to show the importance of health care economics and cost analysis in our current and future practice of neurosurgery. Shockingly, from 1996 to 2010, among PubMed-indexed "neurosurgical" papers, only $2.8 \%$ evoked costs but did not necessarily include a health economics evaluation. ${ }^{9}$ In addition, the quality of economic appraisals has been marginal, mostly because of disparities in methods or a misunderstanding of basic principles. ${ }^{3,8}$ This observation applies to the submissions for this edition on health economics in neurosurgery. Among more than 45 submissions, very few manuscripts had the methodological rigor demanded by modern economic evaluations and cost analyses. Though sobering in their rarity, these select papers offer examples for our field.

Regarding cost analysis, no guidelines or checklists exist to guide authors in preparing strong papers. Until recently, most cost analyses were relatively simple evaluations with only partial assessment of incurred costs. Although published guidelines and checklists exist for the preparation of economic evaluations papers, journals have not necessarily seen an improvement in the quality of submitted works. ${ }^{1,3,4}$ This testifies to the importance of both ensuring that clinicians involved in economic appraisals have basic knowledge in health economics and fostering close collaborations with a multidisciplinary team including economists, decision support staff, administrators, and so forth.

Those analyzing and reporting cost must address several key questions: 1) What type of evaluation is performed (complete economic evaluation vs cost analysis)? 2) How are benefits and/or costs assessed? 3) What component (direct cost, total cost) and source of cost data are used, with clear disclosure if a surrogate is applied (that is, charges or reimbursement fees)? 4) What type of cost data is considered in the analysis (hospital related, physician related, or both)? 5) From whose perspective is the cost assessment (patient, provider, third party payer, societal)? 6) What is the scope of the episode of care for which costs are assessed (surgical encounter only, up to 90 days postdischarge, and so forth)? These questions should help neurosurgeons create well-conducted cost assessments that 1) identify opportunities to deliver 
cost-efficient care and 2) identify cost-containment initiatives that can immediately benefit the provider and the patient. ${ }^{6}$ For additional guidance, an overview of health economics has been included in this issue.

Performing a detailed cost analysis of care - and not just obtaining the total cost of the episode-will be important for departments and systems engaging in bundle pricing initiatives. ${ }^{10}$ Knowledge of the hospital- and physician-related costs will likely facilitate the redistribution of collected payments. Bundle pricing initiatives raise special considerations: 1) population risk adjustment and patient-specific risk adjustment; 2) integration of "risk" in the calculation of standard prices; and 3) management of outliers via different strategies such as "carve-outs" or re-insurance.

To this day, collaborations among clinicians, administrators, finance departments, performance excellence specialists, and economists to lead economic evaluations and cost analyses have been scant. The importance of assessing benefits (outcomes) and related costs, as well as the push for cost transparency in the health system, has facilitated collaborations with finance departments and access to detailed cost data. In order to deliver an issue with methodologically robust and clinically relevant economic evaluations and cost analyses that could serve as examples within the community, a multidisciplinary team of reviewers with special interest and knowledge in health economics was put together. The editors offer their sincere thanks to each reviewer for his or her time and constructive feedback.

We give special thanks to Arun Amar (University of Southern California [USC], Los Angeles, California), Tony Asher (Carolina Neurosurgery and Spine Associates, Charlotte, North Carolina), Prof. James Cunningham (Marshall School of Business, USC, Los Angeles, California), Ralph Dacey (Washington University, Saint Louis, Missouri), Rick Friedman (USC, Los Angeles, California), Steve Gionnatta (USC, Los Angeles, California), Prof. Fred Hagigi (Anderson School of Management, University of California, Los Angeles [UCLA], California), Patrick Hsieh (USC, Los Angeles, California), Thomas Jackiewicz (USC Health Care, Los Angeles, California), Prof. Robert Kaplan (Harvard Business School, Boston, Massachusetts), Mark Liker (USC, Los Angeles, California), Prof. Victor Tabbush (Anderson School of Management, UCLA, Los Angeles, California), and Gabriel Zada (USC, Los Angeles, California).

Neurosurgeons remain leaders in their local communities and national leaders in the treatment of neuro- logical disease. As with previous challenges, we remain confident that neurosurgeons will develop the necessary skill sets to advocate for patients and ensure the availability of resources to support advanced neurosurgical care.

We hope this issue serves as a resource to the $\mathrm{Neu}$ rosurgical Focus readership on this journey, and we look forward to the next chapter in neurosurgical exceptionalism.

(http://thejns.org/doi/abs/10.3171/2014.8.FOCUS14535)

\section{Disclosure}

The authors report no conflict of interest.

\section{References}

1. Chang WY, Henry BM: Methodologic principles of cost analyses in the nursing, medical, and health services literature, 1990-1996. Nurs Res 48:94-104, 1999

2. Chien AT, Rosenthal MB: Medicare's physician value-based payment modifier-will the tectonic shift create waves? N Engl J Med 369:2076-2078, 2013

3. Drummond MF, Jefferson TO, BMJ Economic Evaluation Working Party: Guidelines for authors and peer reviewers of economic submissions to the BMJ. BMJ 313:275-283, 1996

4. Jefferson T, Smith R, Yee Y, Drummond M, Pratt M, Gale R: Evaluating the BMJ guidelines for economic submissions: prospective audit of economic submissions to BMJ and The Lancet. JAMA 280:275-277, 1998

5. Kaplan RS, Porter ME: How to solve the cost crisis in health care. Harv Bus Rev 89:46-52, 54, 56-61 passim, 2011

6. McLaughlin N, Upadhyaya P, Buxey F, Martin NA: Valuebased neurosurgery: measuring and reducing the cost of microvascular decompression surgery. Clinical article. J Neurosurg 121:700-708, 2014

7. Robinson J: Hospitals respond to Medicare payment shortfalls by both shifting costs and cutting them, based on market concentration. Health Aff (Millwood) 30:1265-1271, 2011

8. Robinson R: Economic evaluation and health care. What does it mean? BMJ 307:670-673, 1993

9. Sami Walid M, Robinson JS III, Robinson JS: Shortfalls in published neurosurgical literature. J Clin Neurosci 19:942-945, 2012

10. Scamperle K: The fee-for-service shift to bundled payments: financial considerations for hospitals. J Health Care Finance 39:55-67, 2013

11. Shoemaker W: The cost of quality: how VBP scores correlate with hospital costs. Healthc Financ Manage 66:50-56, 2012

Please include this information when citing this paper: DOI: 10.3171/2014.8.FOCUS14535. 